Thoracic medicine

\section{A man with abdominal pain}

\section{N Rajesh, B Sumathi, K Muthirulandi, J Randhir, V Rajalakshmi, G Muthurangan, R Surendran, V Jayanthi}

Answers on $p 743$.

A 40 year old man presented with intermittent, dull aching abdominal pain of six months' duration. His appetite was good; there was mild weight loss. On examination he was moderately nourished; there were no peripheral palpable lymph nodes. Abdominal examination revealed a tense cystic smooth surfaced, non-

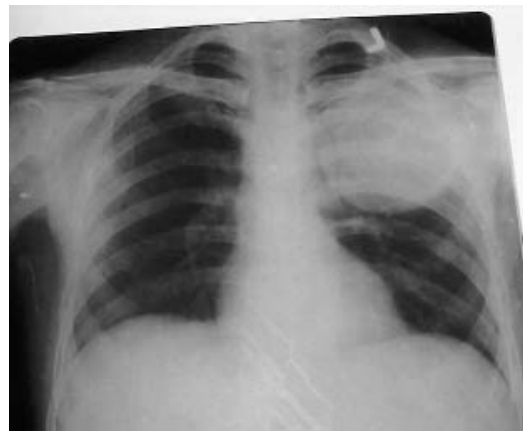

Figure 1 Chest radiograph, posteroanterior view. tender retroperitoneal swelling $(20 \times$ $10 \mathrm{~cm}$ ) in left iliac fossa extending into lumbar and hypogastric region. There was no free fluid in the abdomen. On examination of the chest there was diminished air entry in the left upper zone; his spine was normal. Other system examinations gave normal results.

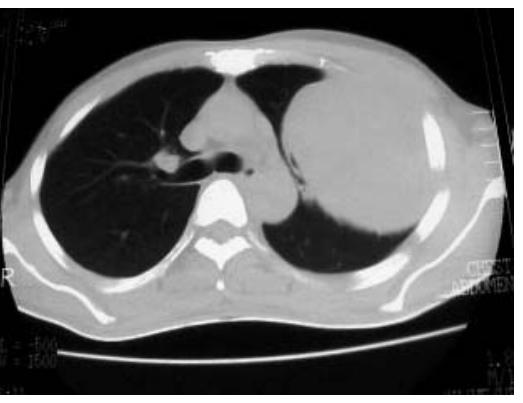

Figure 2 Computed tomogram of chest.

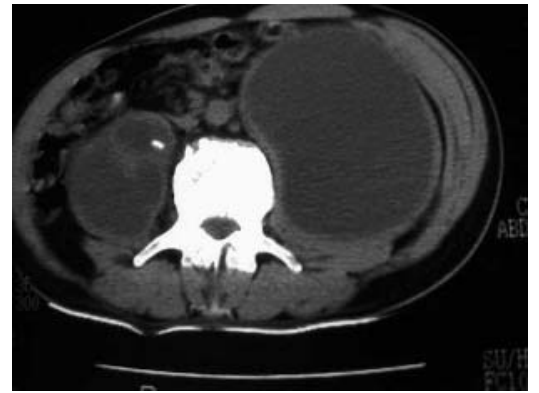

Figure 3 Computed tomogram of abdomen.

\section{QUESTIONS}

(1) What does the chest radiograph show (fig 1)?

(2) What are the findings on computed tomography of the chest (fig 2)?

(3) What are the findings on computed tomography of the abdomen (fig 3 )?

Postgrad Med J 2004;80:741.

doi: 10.1136/pgmi.2004.019869

\section{Authors' affiliations}

N Rajesh, B Sumathi, K Muthirulandi,

J Randhir, V Rajalakshmi, G Muthurangan,

R Surendran, V Jayanthi, Department of

Gastroenterology, Pathology and

Cardiothoracic Surgery, Stanley Medical

College Hospital, Chennai, India

Correspondence to: Dr V Jayanthi, M 97/5 30th Cross Street, Besant Nagar, Chennai 90 India; drjayant1@vsnl.com

Submitted 9 February 2004

Accepted 12 February 2004 